\title{
Ecological Immunology of mosquito-malaria interactions: Of non-natural versus natural model systems and their inferences
}

\author{
F. TRIPET* \\ Center for Applied Entomology and Parasitology, School of Life Sciences - Huxley Building, Keele University Campus, Keele, \\ Staffordshire ST5 5BG, UK
}

(Received 17 February 2009; revised 3 April 2009; accepted 4 April 2009; first published online 2 Fune 2009)

S UMMAR Y

There has been a recent shift in the literature on mosquito/Plasmodium interactions with an increasingly large number of theoretical and experimental studies focusing on their population biology and evolutionary processes. Ecological immunology of mosquito-malaria interactions - the study of the mechanisms and function of mosquito immune responses to Plasmodium in their ecological and evolutionary context - is particularly important for our understanding of malaria transmission and how to control it. Indeed, describing the processes that create and maintain variation in mosquito immune responses and parasite virulence in natural populations may be as important to this endeavor as describing the immune responses themselves. For historical reasons, Ecological Immunology still largely relies on studies based on non-natural model systems. There are many reasons why current research should favour studies conducted closer to the field and more realistic experimental systems whenever possible. As a result, a number of researchers have raised concerns over the use of artificial host-parasite associations to generate inferences about population-level processes. Here I discuss and review several lines of evidence that, I believe, best illustrate and summarize the limitations of inferences generated using nonnatural model systems.

Key words: Anopheles gambiae, Plasmodium falciparum, mosquito-malaria interactions, model systems, inferences, ecological immunology, micro-coevolution, macro-coevolution life history trade-offs, transcriptomes.

\section{INTRODUCTION}

The majority of malaria-associated human mortality is caused by Plasmodium falciparum, a haemosporidian parasite of man that occurs in most tropical and sub-tropical regions of the world and is transmitted by anopheline mosquito species. It has long been recognized that understanding the mosquito immune response to infection by $P$. falciparum may be the key to finding ways of interrupting its transmission. Thus parasitologists and, more recently, insect molecular biologists have focused their research on mosquito immune-related genes and particularly on genes responsible for mosquito refractoriness to the malaria parasite, as well as on parasite-induced fitness costs to mosquito vectors. Since experimental infections of humans or primates are usually not possible much of that research is based on vertebrate/ mosquito/Plasmodium model-systems which, as will be discussed in the next sections, often involve mosquito/Plasmodium associations that do not occur in nature.

* Corresponding Author: Frederic Tripet, Center for Applied Entomology and Parasitology, School of Life Sciences, Huxley Building, Keele University Campus, Keele, Staffordshire ST5 5BG UK. Tel: ++44 1782 733873; Fax: ++44 1782 733516; Email: tripet@ biol.keele.ac.uk
Ecological immunology is a relatively new discipline that focuses on the mechanism and function of immune responses in their ecological context. Since its focus is on population level processes, ecological immunology uses naturally-occurring host-parasite association as model systems. When it comes to research on mosquito/Plasmodium interactions, ecological immunology investigates how ecological factors affect interactions between mosquito vectors and the malaria parasite to create and maintain variation in host immune responses and Plasmodium virulence in natural populations. However, in contrast to what is commonly accepted in Ecological Immunology, when it comes to malaria research, studies of mosquito/Plasmodium interactions still largely rely on the non-natural model-systems used in the past. This paradox forms the basis of the ongoing controversy on the use of model-systems for ecological immunological studies of mosquito/malaria interactions and can be explained by the discipline's dual origins in Evolutionary Ecology and Parasitology.

EVOLUTIONARY ECOLOGY IN THE LATE $1980 \mathrm{~s}-1990 \mathrm{~s}$

In order to understand the foundation of ecological immunology one needs to take a closer look at 
fundamental research in ecology in the late 1980s and 1990s. This period of time saw important transitions in a research discipline that had grown increasingly intolerant of classic observational studies and advocated instead experimentation as the only rigorous way for testing causal relationships between natural processes. Epitomized by the work of Richard Dawkins (Dawkins, 1976), Bill Hamilton (Hamilton, $1964 a, b)$ and others, evolutionary thought had progressively permeated ecology's every topic, effectively bridging it with what was previously known as evolutionary biology whilst paving the way for evolutionary ecology. The study of host-parasite interactions is a particularly dynamic and fastexpanding field of research focusing on topics as diverse as the evolution of parasite virulence (Ewald, 1983; May and Anderson, 1983; Ebert and Herre, 1996), parasite local adaptation (Ebert, 1994; Gandon et al. 1996), and the role of parasites in sexual selection and the evolution of ornaments (Hamilton and Zuk, 1982; Andersson, 1986; Folstad and Karter, 1992). In order to maximize the strength of inferences, the emphasis is deliberately placed on field experiments of natural hosts and parasite populations, as well as on the thoroughness of experimental design and analysis. Parasite-imposed fitness costs are also studied in relation to host life-history trade-offs, such as those between current reproduction and future reproduction or survival (Forbes, 1993; Perrin, Christe and Richner, 1996; Richner and Tripet, 1999). Given their underlying importance in relation to most of the above-mentioned topics, host immune defences received increasing attention and by the mid-nineties, there were enough research groups measuring and manipulating body condition and immune responses in natural host-parasite associations (Lochmiller, Vestey and Boren, 1993; Moller and Saino, 1994; Deerenberg et al. 1997) to warrant a review on that emerging discipline. 'Ecological Immunology : costly parasite defenses and trade-offs in Evolutionary Ecology' (Sheldon and Verhulst, 1996) focuses almost entirely on vertebrate hostparasite associations with the exception of a single study on bumble bees (Konig and Schmid-Hempel, 1995). However, in the next few years insect ecological immunology began to establish itself as a field of research in its own right (Kraaijeveld and Godfray, 1997; Schmid-Hempel and Schmid-Hempel, 1998; Siva-Jothy, Tsubaki and Hooper, 1998; Kurtz, 2000; Rolff and Siva-Jothy, 2003).

\section{THE PRAGMATIC HERITAGE OF PARASITOLOGY}

In stark contrast to evolutionary ecology, parasitology's applied research emphasizes practicality and feasibility, and often relies on non-natural hostparasite model systems to study the life-stages of parasites inside their hosts. Given the impracticality of experimentally infecting primates, studies dating as early as the 1930 s compared the permissiveness of various mosquito species to bird malaria first (Huff, 1927), and later rodent malarias in order to find an alternative model system to human malaria (Garnham, 1963; Killick-Kendrick and Peters, 1978). Ideal mosquito-malaria associations were those in which the malaria parasite completed its entire cycle in a manner comparable to what was known of P. falciparum in its natural vectors (Garnham, 1963; Killick-Kendrick and Peters, 1978). The observed difference in permissiveness between vector species was first considered to be the key to understanding mosquito-malaria interactions; until accumulating evidence that variation in resistance also occurred between individuals within species led researchers to drop that avenue of research altogether (Huff, 1935). Eventually, a limited number of model systems established themselves: the avian malariabased systems Aedes aegypti/Plasmodium gallinaceum and Culex pipiens fatigans/P. cathermerium; and several associations based on rodent malarias, Anopheles gambiae and An. stephensi/Plasmodium berghei and P. yoelii and An. stephensi/P. chabaudi (Garnham, 1963; Yoeli et al. 1965 ; Killick-Kendrick and Peters, 1978). For a long time, model systems involving these unnatural mosquito/Plasmodium associations were the only option for experimental studies of mosquito/ Plasmodium interactions and they make for the vast majority of the current literature on mosquito/ malaria interactions (Tripet, Aboagye-Antwi and Hurd, 2008). The positive side of that heritage is that we know quite a lot about the development of Plasmodium in the mosquito and about the mosquito immune response. The downside, of course, is that much of our current understanding of mosquitoPlasmodium interactions stems from non-natural model systems and remains to be validated using natural associations. This should pave the way for research on the processes that create and maintain variation in mosquito immune responses and Plasmodium development in natural populations (Boete, 2005 ; Tripet et al. 2008).

MOSQUITO-PLASMODIUM MODEL SYSTEMS AND THEIR INFERENCES

One can see how the focus of evolutionary biologists on fundamental research, their evolutionary considerations and awareness of experimental designs and the strength of inferences will drive them away from non-natural systems which-in their viewcannot generate inferences applicable to the 'real world' of natural populations. This view has to be contrasted with that of parasitologists who consider studying life-threatening diseases a priority that warrants the development of practical laboratorybased model systems in order to conduct applied research ultimately leading to disease control. Today's literature on the ecological immunology of 


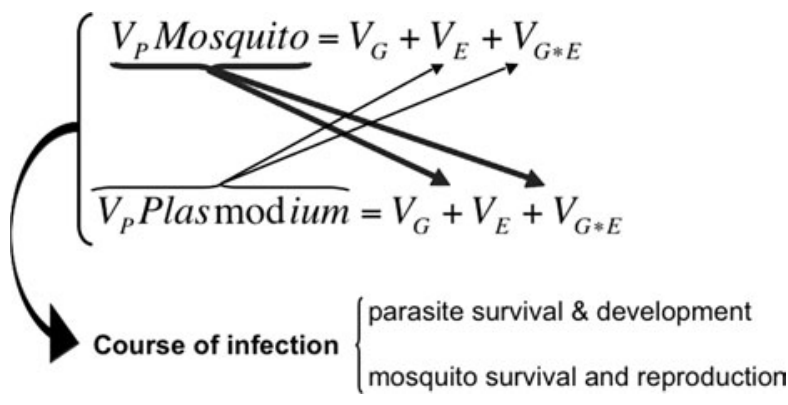

Fig. 1. Phenotypic variance components in infected mosquitoes (first equation) and in Plasmodium parasites (second equation). Where $V_{P}$ is the phenotypic variance among individuals, $V_{G}$ the genetic variance, $V_{E}$ the variance due to the direct effect of the environment, and $V_{G * E}$ the genotype-by-environment interaction, which occurs when the effect of the environment differs among genotypes. Thus, the phenotypic variance observed among hosts and parasites in natural populations is due to genetic and environmental factors as well as the interactions between the two. Both host and parasites strongly influence the course of infection and their respective phenotypic variances can be considered an essential component of each other's 'environment' that strongly affect their $V_{E}$ and $V_{G^{*} E}$ terms.

mosquito/Plasmodium interactions reflects these contrasted heritages (Tripet et al. 2008). In the following sections, I will discuss several aspects of hostparasite interactions that clarify the limitations of non-natural model systems and emphasize the importance of ecological immunological studies based on natural associations.

\section{Host-parasite interactions as a complex phenotype}

In the natural environment, the outcome of mosquito infections with Plasmodium gametocytes are particularly complex phenotypes (Fig. 1). In simple quantitative genetics terms the variation observed in such phenotypes can be summarized by two equations: The first one describing the phenotypic variation in the infected mosquitoes (e.g. survival, immune response level and body condition) which is determined by variation in mosquito genetic and environmental factors, and interactions between those factors; and the second one describing the phenotypic variance of the infecting Plasmodium parasites (survival, multiplication, rate of development, etc.) which is determined by variation in parasite genetic and environmental factors and interactions between those factors (Tripet et al. 2008). Both host and parasites equations strongly influence the outcome of infections and their respective phenotypic variances can be considered an essential component of each other's 'environment' (Fig. 1). The importance of mosquito and Plasmodium genetic and environmental factors on parasite development and virulence - i.e. parasite-induced fitness costs to the host in the form of decreased fertility or survival (see discussion below) - has been demonstrated using non-natural model-systems and in a few studies of natural associations (reviewed in Tripet et al. 2008).

One of the challenges of ecological immunology is to help understand how ecological factors affect mosquito/malaria interactions to create and maintain variation in mosquito immune defence and Plasmodium virulence in natural populations. In this regard, laboratory-based studies are constrained by a variety of factors that tend to decrease phenotypic variation among individuals through various selection pressures (Table 1). This is true even in laboratory studies of natural mosquito/Plasmodium associations whose inferences should be more easily extrapolated to natural populations than those from non-natural associations. Generally, the lack of phenotypic variation in mosquitoes and parasites that characterizes laboratory experiments limits our ability to study the whole palette of host-parasite interactions (Table 1). However, laboratory-based studies conducted far away from malaria endemic countries are not the only option available to researchers. Indeed, the increasing large number of facilities dedicated to malaria research in African countries makes it ever easier for studying mosquitomalaria interactions nearer to the field (Table 2).

\section{Host-parasite coevolution and local adaptation}

Coevolution between hosts and their parasites is commonly seen as an evolutionary arms race between populations of parasites that evolve to maximize their fitness, which depends on their successful transmission to new hosts, and population of hosts that evolve mechanisms to limit their own fitness loss to parasites (Price, 1980, 1984; Poulin, Morand and Skorping, 2000). In doing so, hosts exert selection pressures on their parasites and, reciprocally, parasites exert selection pressures on their host, something that can readily be understood in mosquito/ Plasmodium association given how strongly they are expected to affect each other's fitness components (see Fig. 1). One must keep in mind that reciprocal selection also occurs between the vertebrate hosts and the asexual Plasmodium stages; hence malaria evolution is essentially an intimate, triangular affair between parasite, vector and vertebrate hosts. In this regard, it is worth remembering that human, rodent and bird malarias cannot develop in each other's vertebrate hosts thereby underlining crucial genetic differences between those parasites.

Detecting and quantifying host-parasite coevolution is not a simple task especially when parasite specificity is low. In parasites with high specificity, such as Plasmodium, coevolution translates in congruence between the host and parasite phylogenies in what is commonly know as phylogenetic tracking (Poulin, 2007). Recovering the macroevolutionary 
Table 1. Common factors associated with laboratory-based experiments that negatively affect studies of mosquito-malaria interactions

\begin{tabular}{|c|c|c|c|}
\hline $\begin{array}{l}\text { Phenotypic Variance } \\
\text { component } \dagger\end{array}$ & Source of bias & Processes & Consequences \\
\hline Mosquito genetic variance & Laboratory conditions & $\begin{array}{l}\text { Selection for mating in } \\
\text { cage } \\
\text { Selection for oviposition } \\
\text { in cage } \\
\text { Selection for lab-specific } \\
\text { breeding scheme } \\
\text { Inbreeding }\end{array}$ & $\begin{array}{l}\text { Limited number of } \\
\text { strains available with } \\
\text { limited genetic variation }\end{array}$ \\
\hline $\begin{array}{l}\text { Mosquito environmental } \\
\text { variance }\end{array}$ & Laboratory conditions & $\begin{array}{l}\text { Lab-specific stable } \\
\text { environmental conditions }\end{array}$ & $\begin{array}{l}\text { Limited environmental } \\
\text { variance }\end{array}$ \\
\hline $\begin{array}{l}\text { Mosquito genetic*environmental } \\
\text { variance }\end{array}$ & $\begin{array}{l}\text { Colonization and } \\
\text { laboratory conditions }\end{array}$ & See above & $\begin{array}{l}\text { Limited genetic* } \\
\text { environmental variance }\end{array}$ \\
\hline Plasmodium genetic variance & $\begin{array}{l}\text { Isolation } \\
\text { Cloning } \\
\text { Culturing } \\
\text { Mosquito infections }\end{array}$ & $\begin{array}{l}\text { Selection for in vitro culturing } \\
\text { Intentional control of } \\
\text { genetic background } \\
\text { Selection for lab-specific } \\
\text { culturing scheme } \\
\text { Selection for gametocyte } \\
\text { infectivity }\end{array}$ & $\begin{array}{l}\text { Limited number of } \\
\text { strains available with } \\
\text { limited genetic variation }\end{array}$ \\
\hline $\begin{array}{l}\text { Plasmodium environmental } \\
\text { variance }\end{array}$ & Laboratory conditions & $\begin{array}{l}\text { Lab-specific environmental } \\
\text { conditions affecting } \\
\text { mosquitoes (see above) } \\
\text { and/or Plasmodium }\end{array}$ & $\begin{array}{l}\text { Limited environmental } \\
\text { variance }\end{array}$ \\
\hline $\begin{array}{l}\text { Plasmodium genetic* } \\
\text { environmental variance }\end{array}$ & $\begin{array}{l}\text { Isolation } \\
\text { Cloning } \\
\text { Culturing } \\
\text { Mosquito infections } \\
\text { Laboratory conditions }\end{array}$ & See above & $\begin{array}{l}\text { Limited genetic* } \\
\text { environmental variance }\end{array}$ \\
\hline
\end{tabular}

$\dagger$ Note that the importance of some of these factors has been tested experimentally (reviewed in (Tripet et al. 2008)).

* This corresponds to a multiplication sign (see Fig. 1).

Table 2. Commonly available options to study naturally-occurring interactions between Anopheles gambiae and Plasmodium falciparum

\begin{tabular}{|c|c|c|}
\hline Experiments conducted with: & Advantages & Disadvantages \\
\hline $\begin{array}{l}\text { Naturally infected wild-caught } \\
\text { blood-fed female mosquitoes }\end{array}$ & $\begin{array}{l}\text { Natural genetic variation in } \\
\text { mosquitoes and parasite }\end{array}$ & $\begin{array}{l}\text { No control of mosquito age } \\
\text { No control of previous infection } \\
\text { Only feasible in areas highly endemic } \\
\text { for malaria }\end{array}$ \\
\hline $\begin{array}{l}\text { Progeny of wild-caught blood-fed } \\
\text { female mosquitoes fed infected blood } \\
\text { from patient }\end{array}$ & $\begin{array}{l}\text { Natural genetic variation in } \\
\text { mosquitoes and parasite } \\
\text { Control of age } \\
\text { No previous infection }\end{array}$ & $\begin{array}{l}\text { Only feasible in endemic malaria } \\
\text { areas } \\
\text { Only a fraction of individuals will } \\
\text { feed on membranes }\end{array}$ \\
\hline $\begin{array}{l}\text { Colonized mosquitoes fed } \\
\text { gametocytes produced in vitro }\end{array}$ & $\begin{array}{l}\text { Feasible away from malaria } \\
\text { endemic areas } \\
\text { Full control of experimental } \\
\text { conditions }\end{array}$ & $\begin{array}{l}\text { Costly infrastructure } \\
\text { Mosquitoes with little genetic } \\
\text { variation and heavily selected (see } \\
\text { Table 1) } \\
\text { Parasites with little genetic variation } \\
\text { and heavily selected (see Table 1) }\end{array}$ \\
\hline
\end{tabular}

history of Plamodium and other Haemosporidia has kept systematic parasitologists confused for decades and, until recently, there was still considerable debate on the most likely common ancestor of P. falciparum (Roy and Irimia, 2008). The most recent and complete analyses included sequence data from the nuclear, mitochondrial and plastid genomes
(Perkins, Sakar and Carter, 2007; Martinsen, Perkins and Schall, 2008) and compared the distribution of rare indels in the rDNA and full mitochondrial genomes in a large number of Haemosporidia (Roy and Irimia, 2008). The results from both approaches do not support a common $P$. falciparum and rodent malaria clade but suggest instead 


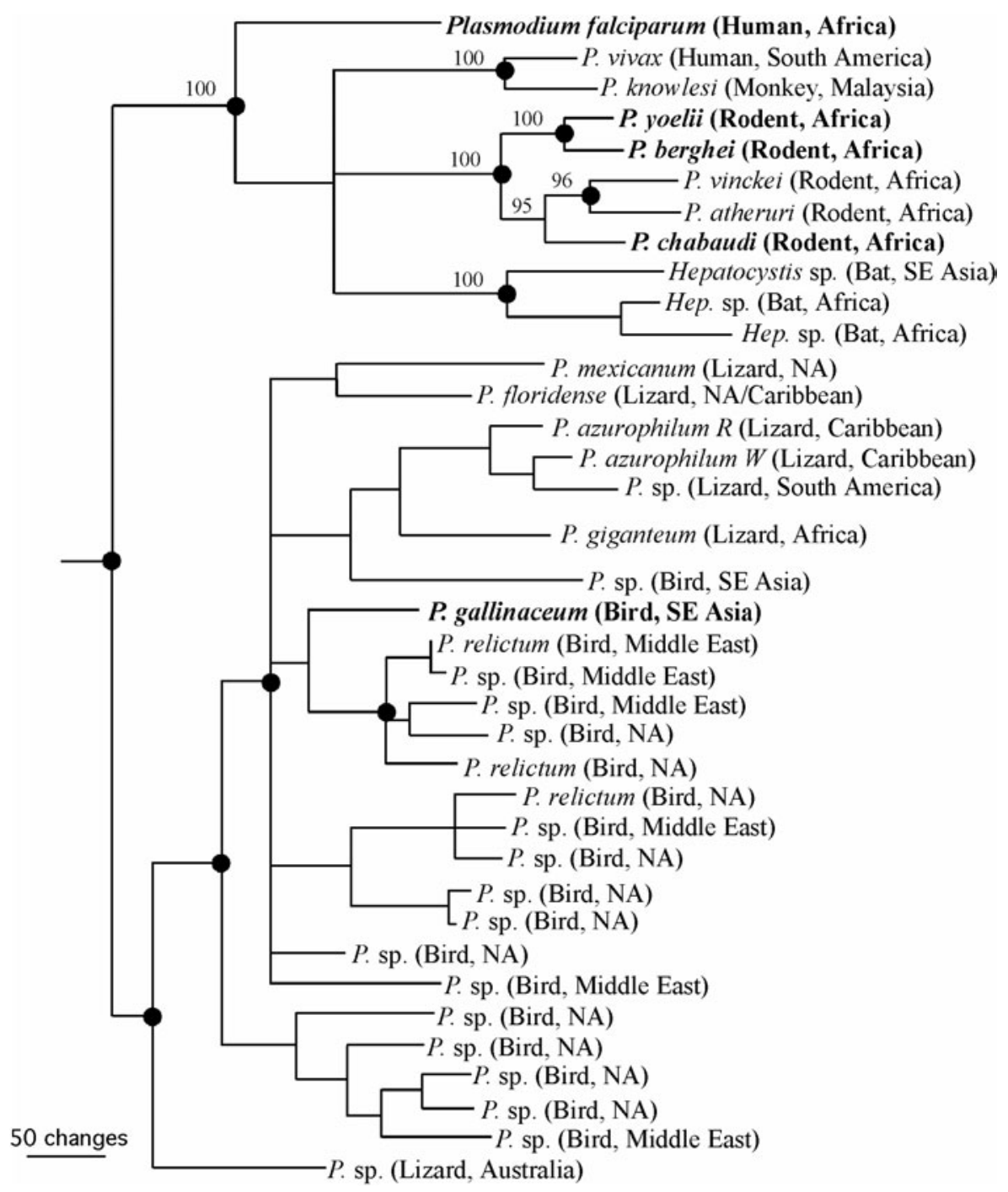

Fig. 2. Majority-rule consensus phylogram recovered using maximum parsimony and Bayesian analyses of four genes across the parasite three genomes (modified with permission from (Martinsen et al. 2008). Only part of the tree is presented here. Rodent and avian malarias commonly used in studies of mosquito/Plasmodium interactions are in bold. Dots on notes indicate $\geqslant 95 \%$ posterior probability support nodal support values estimated by Bayesian analysis. Parsimony bootstrap values greater or equal to $95 \%$ are also indicated. Taxon labels are the genus based on morphology seen in microscope blood smears, and species when that identification could be made with confidence. Vertebrate hosts and region of samples are indicated.

that they share a distant ancestor (Fig. 2) (Martinsen et al. 2008; Roy and Irimia, 2008). The hypothesis of a common origin with bird malaria (Waters, Higgins and McCutchan, 1991, 1993) is not supported either. $P$. falciparum sequence data is very distinct from those distant relatives. For example, there is an average $14 \cdot 1 \%$ DNA sequence divergence (range $12 \cdot 3-15 \cdot 3 \%$ ) between $P$. falciparum and any of the rodent malarias whilst the average level of divergence between all rodent malarias is $6 \cdot 4 \%$ (Martinsen personal communication). P. falciparum's closest relative would be the simian-human malaria parasite $P$. reichenowi (Roy and Irimia, 2008). Thus, these results provide evidence of some level of phylogenetic tracking between the phylogenies of Plasmodium and that of their vertebrate hosts. Using the mutation rate in the sequence of the small subunit ribosomal
RNA and circumsporozoite surface protein genes as molecular clocks Escalante et al. (Escalante and Ayala, 1994, 1995) estimated that $P$. falciparum may have split from its simian ancestor $\sim 8-10$ millions of years ago an event that may have coincided with the split between hominids and other great apes. Phylogenetic tracking between Plasmodium species and their insect vectors is more diffuse given that Plasmodium species are commonly transmitted by several mosquitoes species. However, evidence of phylogenetic tracking can still be detected at higher taxonomic levels. In their study, for example, Martinsen et al. (2008) show that all Plasmodium species fall within a single well-supported clade and that they are all transmitted by mosquitoes (Culicidae) apart from a single exception. Similarly, other genera of haemosporidia tended to form distinct clades each 
transmitted by different Dipteran vector families (Martinsen et al. 2008).

Because parasites have typically shorter generation times and higher migration rates, and are under stronger selection pressure than their hosts, they are predicted to be adapted to their local host populations (Price, 1980; Gandon and Michalakis, 2002). Transplantation experiments are thus another approach to reveal coevolution, this time at the microevolutionary scale. Such studies compare the average parasite reproductive rate between combinations of sympatric and allopatric host and parasite populations. Local adaptation of parasites, which translates into higher reproductive rates of the parasite on sympatric hosts has been found only in some of the studies that tested for it (Ebert, 1994; Prugnolle et al. 2006). As shown by theoretical studies and a recent meta-analysis of all published studies on local adaptation, the likelihood that parasites will be more adapted to their local host depends on the migration rate of the parasite considered (Gandon and Michalakis, 2002; Greischar and Koskella, 2007).

Regardless of the direction of changes in parasite reproductive rate found in transplantation experiments, such significant difference between host and parasite populations within their species underline the importance of ongoing local coevolutionary processes. In natural mosquito/Plasmodium associations, recent experiments have showed evidence of local adaptation or differences between allopatric versus sympatric mosquito and Plasmodium populations in An. gambiae and An. stephensi infected with P. falciparum, and in An. pseudopunctipennis and An. albimanus infected with P. vivax (Hume et al. 2007; Joy et al. 2008).

\section{Trade-offs between fitness and immune defences}

Given the strong evidence for the occurrence of micro and macro-coevolution between Plasmodium and its hosts, it is not surprising that few of the non-natural mosquito/Plasmodium combinations examined by parasitologists have been found to complete their exogenous life stages in a natural association-like fashion. From an evolutionary biologist's point of view, the optimization of non-natural mosquito/Plasmodium model systems essentially gives up on coevolutionary considerations and is equivalent to creating artificial host-switches. Host switches, of course, do occur in nature; but they are essentially chance events often accompanied by increased virulence of parasites on their new permissive hosts (Ebert and Herre, 1996).

Due to the limited number of publications available on natural mosquito/Plasmodium interactions, quantifying differences between unnatural model systems versus natural associations is difficult. One aspect of infection for which such comparison has been possible are potential Plasmodium-induced fitness costs in terms of mosquito survival (Ferguson and Read, 2002). In a particularly interesting metaanalysis of the limited number of studies available on this topic, Ferguson and Read (2002) found a significant negative effect of Plasmodium on mosquito survival across the literature based on non-natural model systems but not in studies focusing on natural associations. These results confirm the expectation that artificial mosquito/Plasmodium model-systems may only crudely replicate natural interactions and may be associated with higher parasite virulence.

\section{Molecular biology of mosquito immune responses}

Thanks to whole-genome transcript analysis, molecular biologists working on mosquito immune responses now have powerful tools to quantitatively and qualitatively compare natural and non-natural associations. Consequently, they too have repeatedly emphasized the limitations of non-natural modelsystems (Cohuet et al. 2006; Dong et al. 2006; Michel et al. 2006). For example, Dong and colleagues (2006) in a comparison of An. gambiae's gene expression during invasion of the midgut with $P$. falciparum and P. berghei, found stark differences in the number of regulated genes. In P. falciparum infections, 471 genes corresponding to $3 \cdot 4 \%$ of the transcriptome were regulated in contrast to $P$. berghei infections where no less than 1102 genes or $8 \cdot 1 \%$ of the transcriptome changed (Dong et al. 2006). Importantly, studies looking at the function of individual immunity-related genes through reverse genetics found that only a fraction of those genes affected infections with human and rodent malaria in a comparable manner (Dong et al. 2006; Mendes et al. 2008). Immunity genes whose importance for human malaria has been validated through experimental studies of the natural mosquito/Plasmodium association are thought to be essential and ancestral components of the mosquito's immune's response architecture (Mendes et al. 2008).

\section{CONCLUSIONS}

Whilst artificial model-systems obviously must retain some basic characteristics of the natural associations of their host and parasite components, it is difficult to assess just how much can be learned from artificial model systems and how much will have to be re-visited using natural associations (Tripet et al. 2008). The potential severity of the problems associated with inferences generated through the study of non-natural parasite associations partially depends on the questions asked. Whilst we can reasonably assume that fundamental or ancestral-like physiological and developmental characteristics are shared between all vertebrate malarias, the same cannot be said of questions relating to population biology and micro-evolutionary processes. The problems and 
concerns discussed above have been hinted at or voiced by an increasing number of researchers including evolutionary biologists, molecular biologists and parasitologists (Boete, 2005; Cohuet et al. 2006; Dong et al. 2006; Martinsen et al. 2008). Indeed, understanding how ecological factors affect mosquito/malaria interactions to create and maintain variation in mosquito immune defence and Plasmodium virulence in natural populations is generally recognized as paramount to our quest to resolve the malaria problem. However, recognizing that further advances in this field strongly depend on increasing our research effort based on studies of natural vector/Plasmodium associations whilst simultaneously minimizing the use of non-natural ones is still not fully accepted. It is hoped that the above discussion will serve as a strong incentive, for studying mosquito/Plasmodium interactions using P. falciparum and its natural vectors, and for doing so closer to the field.

\section{ACKNOWLEDGMENTS}

I thank Ellen Martinsen for her estimates of sequence divergence and Hilary Hurd, Fred Aboagye-Antwi, Doug Paton as well as two anonymous referees for their comments on the manuscript.

\section{REFERENCES}

Andersson, M. (1986). Evolution of condition-dependent sex ornaments and mating preferences - sexual selection based on viability differences. Evolution 40, 804-816.

Boete, C. (2005). Malaria parasites in mosquitoes: laboratory models, evolutionary temptation and the real world. Trends in Parasitology 21, 445-447.

Cohuet, A., Osta, M. A., Morlais, I., Awono-Ambene, P. H., Michel, K., Simard, F., Christophides, G. K., Fontenille, D. and Kafatos, F. C. (2006). Anopheles and Plasmodium: from laboratory models to natural systems in the field. EMBO Report 7, 1285-1289.

Dawkins, R. (1976). The Selfish Gene, Oxford, Oxford University Press.

Deerenberg, C., Arpanius, V., Daan, S. and Bos, N. (1997). Reproductive effort decreases antibody responsiveness. Proceedings of the Royal Society of London B 264, 1021-1029.

Dong, Y., Aguilar, R., Xi, Z., Warr, E., Mongin, E. and Dimopoulos, G. (2006). Anopheles gambiae immune responses to human and rodent Plasmodium parasite species. PLoS Pathogens 2, e52.

Ebert, D. (1994). Virulence and local adaptation of a horizontally transmitted parasite. Science $\mathbf{2 6 5}$, 1084-1086.

Ebert, D. and Herre, E. A. (1996). The evolution of parasitic diseases. Parasitology Today 12, 96-101.

Escalante, A. A. and Ayala, F. J. (1994). Phylogeny of the malarial genus Plasmodium, derived from ribosomalRNA gene-sequences. Proceedings of the National Academy of Sciences, USA 91, 11373-11377.

Escalante, A. A. and Ayala, F. J. (1995). Evolutionary origin of Plasmodium and other Apicomplexa based on
ribosomal-RNA genes. Proceedings of the National Academy of Sciences, USA 92, 5793-5797.

Ewald, P. W. (1983). Host-parasite relations, vectors, and the evolution of disease severity. Annual Review Ecology and Systematics 14, 465-485.

Ferguson, H. M. and Read, A. F. (2002). Why is the effect of malaria parasites on mosquito survival still unresolved? Trends in Parasitology 18, 256-261.

Folstad, I. and Karter, A. J. (1992). Parasites, bright males and the immunocompetence handicap. American Naturalist 139, 603-622.

Forbes, M. R. L. (1993). Parasitism and host reproductive effort. OIKOS 67, 444-450.

Gandon, S., Capowiez, Y., Dubois, Y., Michalakis, Y. and Olivieri, I. (1996). Local adaptation and gene-forgene coevolution in a metapopulation model. Proceedings of the Royal Society of London B 263, 1003-1009.

Gandon, S. and Michalakis, Y. (2002). Local adaptation, evolutionary potential and host-parasite coevolution: interactions between migration, mutation, population size and generation time. Fournal of Evolutionary Biology 15, 451-462.

Garnham, P. C. (1963). Malaria Parasites and Other Haemosporida, Blackwell Scientific Publications, Oxford.

Greischar, M. A. and Koskella, B. (2007). A synthesis of experimental work on parasite local adaptation. Ecology Letters 10, 418-434.

Hamilton, W. D. (1964a). The genetical evolution of social behavior. II. Fournal of Theoretical Biology 7, 17-52.

Hamilton, W. D. (1964b). The genetical evolution of social behaviour. I. Fournal of Theoretical Biology 7, $1-16$.

Hamilton, W. D. and Zuk, M. (1982). Heritable true fitness and bright birds : a role for parasites? Science 218, 384-387.

Huff, C. G. (1927). Studies on the infectivity of Plasmodia of birds for mosquitoes with special reference to the problem of immunity in the mosquito. American Fournal of Tropical Medicine and Hygiene 7, 706-734.

Huff, C. G. (1935). Natural immunity and susceptibility of culicine mosquitoes to avian malaria. American Fournal of Tropical Medicine and Hygiene 15, 427-434.

Hume, J. C. C., Tunnicliff, M., Ranford-Cartwright, L. C. and Day, K. P. (2007). Susceptibility of Anopheles gambiae and Anopheles stephensi to tropical isolates of Plasmodium falciparum. Malaria Fournal 6, 139. doi: 10.1186/1475-2875-6-139.

Joy, D. A., Gonzalez-Ceron, L., Carlton, J. M., Gueye, A., Fay, M., Mccutchan, T. F. and Su, X. Z. (2008). Local adaptation and vector-mediated population structure in Plasmodium vivax malaria. Molecular Biology and Evolution 25, 1245-1252.

Killick-Kendrick, R. and Peters, W. (1978). Rodent Malaria. Academic Press, London, New York, San Francisco.

Konig, C. and Schmid-Hempel, P. (1995). Foraging activity and immunocompetence in workers of the bumble bee, Bombus terrestris L. Proceedings of the Royal Society of London B 260, 225-227.

Kraaijeveld, A. R. and Godfray, H. C. (1997). Trade-off between parasitoid resistance and larval competitive ability in Drosophila melanogaster. Nature 389, 278-280. 
Kurtz, J. (2000). Gender differences and individual variation in the immune system of the scorpionfly Panorpa vulgaris (Insecta: Mecoptera). Developmental and Comparative Immunology 24, 1-12.

Lochmiller, R. L., Vestey, M. R. and Boren, J. C. (1993). Relationship between protein nutritional-status and immunocompetence in northern bobwhite chicks. Auk 110, 503-510.

Martinsen, E. S., Perkins, S. L. and Schall, J. J. (2008). A three-genome phylogeny of malaria parasites (Plasmodium and closely related genera): evolution of life-history traits and host switches. Molecular Phylogenetics and Evolution 47, 261-273.

May, R. M. and Anderson, R. M. (1983). Epidemiology and genetics in the coevolution of parasites and hosts. Proceedings of the Royal Society of London B 219, 281-313.

Mendes, A. M., Schlegelmilch, T., Cohuet, A., Awono-Ambene, P., De Iorio, M., Fontenille, D., Morlais, I., Christophides, G. K., Kafatos, F. C. and Vlachou, D. (2008). Conserved mosquito/parasite interactions affect development of Plasmodium falciparum in Africa. PLoS Pathogens 4, e1000069.

Michel, K., Suwanchaichinda, C., Morlais, I., Lambrechts, L., Cohuet, A., Awono-Ambene, P. H., Simard, F., Fontenille, D., Kanost, M. R. and Kafatos, F. C. (2006). Increased melanizing activity in Anopheles gambiae does not affect development of Plasmodium falciparum. Proceedings of the National Academy of Science, USA 103, 16858-16863.

Moller, A. P. and Saino, N. (1994). Parasites, immunology of hosts, and host sexual selection. Fournal of Parasitology 80, 850-858.

Perkins, S. L., Sarkar, I. N. and Carter, R. (2007). The phylogeny of rodent malaria parasites: simultaneous analysis across three genomes. Infection Genetics and Evololution 7, 74-83.

Perrin, N., Christe, P. and Richner, H. (1996). On host life-history response to parasitism. Oikos 79, 317-320.

Poulin, R. (2007). Evolutionary Ecology of Parasites. 2nd Edn. Princeton University Press.

Poulin, R., Morand, S. and Skorping, A. (2000). Evolutionary Biology of Host-Parasite Relationships : Theory Meets Reality. Elsevier Health Sciences.

Price, P. W. (1980). Evolutionary Biology of Parasites, Princeton University Press.

Price, P. W. (1984). Chapter 6: Parasite and host interactions. In Insect Ecology, 2nd Edn. John Wiley \& Sons, New York.
Prugnolle, F., De Meeus, T., Pointier, J. P., Durand, P., Rognon, A. and Theron, A. (2006).

Geographical variations in infectivity and susceptibility in the host-parasite system Schistosoma mansonil

Biomphalaria glabrata: no evidence for local adaptation. Parasitology 133, 313-319.

Richner, H. and Tripet, F. (1999). Ectoparasitism and the trade-off between current and future reproduction. Oikos 86, 535-538.

Rolff, J. and Siva-Jothy, M. T. (2003). Invertebrate ecological immunology. Science 301, 472-475.

Roy, S. W. and Irimia, M. (2008). Origins of human malaria: rare genomic changes and full mitochondrial genomes confirm the relationship of Plasmodium falciparum to other mammalian parasites but complicate the origins of Plasmodium vivax. Molecular Biology and Evolution 25, 1192-1198.

Schmid-Hempel, R. and Schmid-Hempel, $\mathbf{P}$. (1998). Colony performance and immunocompetence of a social insect,Bombus terrestris, in poor and variable environments. Functional Ecology 12, 22-30.

Sheldon, B. C. and Verhulst, S. (1996). Ecological immunology: costly parasite defences and trade-offs in evolutionary ecology. Trends in Ecology and Evolution 11, 317-321.

Siva-Jothy, M. T., Tsubaki, Y. and Hooper, R. (1998). Decreased immune response as a proximate cost of copulation and oviposition in a damselfly. Physiological Entomology 23, 274-277.

Tripet, F., Aboagye-Antwi, F. and Hurd, $H$. (2008). New horizons: ecological immunology of mosquito-malaria interactions. Trends in Parasitology 24, 219-227.

Waters, A. P., Higgins, D. G. and McCutchan, T. F. (1991). Plasmodium falciparum appears to have arisen as a result of lateral transfer between avian and human hosts. Proceedings of the National Academy of Science USA 88, 3140-3144.

Waters, A. P., Higgins, D. G. and McCutchan, T. F. (1993). Evolutionary relatedness of some primate models of Plasmodium. Molecular Biology and Evolution 10, 914-923.

Yoeli, M., Vanderberg, J., Nawrot, R. and Most, H. (1965). Studies on sporozoite-induced infections of rodent malaria II. Anopheles stephensi as an experimental vector for Plasmodium Berghei. American Yournal of Tropical Medicine and Hygiene 14, 927-930. 